\title{
Biochemical methods in nutritional assessment
}

\author{
By H. F. WooDs, University Department of Therapeutics, The Royal Hallamshire \\ Hospital, Sheffield Sro $2 \mathfrak{Z F}$
}

The availability of methods for the nutritional therapy of hospital patients has caused clinicians to realize the need for reliable methods to select patients for such treatment.

In the early years, following the introduction of the techniques of parenteral nutrition and enteral nutrition, the decision to use those therapies was mostly a clinical one. More recently attempts have been made to employ methods of nutritional assessment to select patients for therapy on the basis that they are 'malnourished'. This paper is a critical discussion of the use of biochemical methods in the nutritional assessment of hospital patients.

\section{How has clinically significant malnutrition been defined and detected?}

Methods for the study of the nutritional status of populations are well established and have been available since 1939 when Bigwood described standards for use with such methods. The information needed for an assessment of the nutritional status of populations falls into four main groups:

I. Clinical observation and examination

2. Anthropometric measurements

3. Biochemical measurements

4. Dietary history

The amount of such information is large (e.g. WHO, r $96_{3}$ ) and in the context of the care of hospital patients is not directly applicable for two reasons. Firstly because of the quantity of data required and secondly because the standard methods of assessment apply to populations, not to individuals. In hospital practice biochemical methods have been used in several ways to define and detect malnutrition.

The decision to use nutritional therapy is mostly a clinical one based upon a bedside clinical assessment and a large body of experience which suggests that such treatment is effective. Increasingly, however, attempts are being made to use nutritional measurements, including biochemical methods, to select patients for therapy. These are discussed below.

\section{The incidence of abnormal nutritional measurements within the hospital population}

One of the main justifications for the use of nutritional therapy has been the high incidence of abnormal nutritional measurements within populations of surgical and medical patients in hospital. Surveys carried out in the USA and the UK have 
shown that up to $50 \%$ of those examined had anthropometric or biochemical measurements below the norm for the general population (Bollett \& Owens, r973; Bistrian et al. 1974, 1976; Hill et al. 1977). An example taken from the work of Hill et al. 1977 is shown in Table I. Hill et al. (1977) showed a worsening of some measurements during the hospital stay and that in some instances the abnormal measurements had not been recognized and were thus not corrected by treatment.

Such studies have used a limited number of measurements and are now widely quoted as demonstrating the common occurrence of malnutrition among hospital patients. However, it is reasonable to ask whether the presence of a single measurement or a combination of measurements which are below the 90 or $95 \%$ confidence limits for a normal population proves the presence of malnutrition.

\section{Nutritional assessment schemes}

The selection of patients for nutritional therapy involves a consideration of those factors which justify the use of that therapy. The importance of the nutritional state in determining the clinical outcome among surgical patients has been recognized for many years (Studley, 1936) and since then the relationship between nutritional state and the post-operative morbidity and mortality of patients has been widely studied. It is within this context that clinically significant abnormalities of nutrition have been defined for hospital patients and not in relation to the normal nutriture. Thus many studies have identified those nutritional measurements which, when they are abnormal, identify those patients who have an increased risk of post-operative morbidity and mortality. A summary of some recent studies is given in Table 2. The measurements include biochemical tests and there is close agreement between authors as to the most reliable measurements.

\section{Table $\mathrm{I}$. The nutritional state of unselected surgical inpatients}

These data have been abstracted from the paper of Hill et al. (1977). Each patient was assigned to the low value group on the basis of either comparison with standard tables of values (anthropometric measurements) or with a control group

Measurement
Weight/height
Triceps skinfold thickness
Arm muscle circumference
Serum albumin
Haemoglobin
Plasma transferrin
Leucocyte ascorbic acid
Red cell
Folate
Vitamin $\mathbf{B}_{12}$
Vitamin $\mathbf{B}_{6}$

$\%$ Of patients with a low value

21
56
48
26
20
4 I
34
24
20
6


Table 2. Markers of increased morbidity and mortality in surgical patients

$\begin{array}{ll}\begin{array}{l}\text { Measurements } \\ \text { Serum transferrin }\end{array} & \begin{array}{l}\text { Reference } \\ \text { Serum albumin }\end{array} \\ \begin{array}{l}\text { Delayed hypersensitivity reactivity } \text { et al. } \text { (1979) } \\ \text { Serum transferrin }\end{array} & \\ \text { Delayed hypersensitivity reactivity } & \text { Kaminski } \text { et al. (1977) } \\ \text { Serum albumin } & \text { Meakins } \text { et al. } \text { (1977) } \\ \text { Triceps skinfold thickness } & \text { Buzby } \text { et al. (1980) } \\ \text { Serum transferrin } & \\ \text { Delayed hypersensitivity reactivity } & \\ \text { Hand grip dynam } & \\ \text { Arm muscle circumference } & \text { Klidjian } \text { et al. (1980) } \\ \text { Weight for height } & \\ \text { Serum albumin } & \end{array}$

Once these measurements were identified it was logical to use them to pick out those patients who were 'at risk' in terms of subsequent morbidity and mortality and then use nutritional therapy to correct the abnormalities with the aim of improving the outcome for the patient. The measurements have formed the basis of a number of schemes of nutritional selection. Methods of varying complexity are available (Butterworth \& Blackburn, 1976; Blackburn et al. 1977; Kaminski \& Winborn, 1978). An examination of these schemes shows them to have several features in common so far as the individual nutritional measurements are concerned. They all contain a mixture of anthropometric, biochemical and immunological measurements. In addition, analysis of the content of such schemes has shown that the majority of these measurements are included because they are known indicators of morbidity and mortality (Woods et al. 1980 ). One example to illustrate this is given in Table 3 . This Table shows a list of measurements which are included in the UCLA hospital and clinics nutritional assessment sheet. This sheet is designed to help a clinician to make the decision to use nutritional therapy and to grade the severity of the nutritional abnormalities detected. When the measurements in this sheet are considered it is clear that many of them are

\section{Table 3. A nutritional assessment sheet}

The Table summarizes the nutritional assessment data sheet used in the UCLA hospital and clinics. The measurements marked with an asterisk are known to be indicators of post-operative morbidity and mortality as described in the text.

$\begin{array}{ll}\text { Somatic parameters } & \text { Visceral parameters } \\ \text { \% Ideal body-weight } & \text { Serum albumin* } \\ \text { Triceps skinfold thickness* } & \text { Serum transferrin* } \\ \text { Mid-arm circumference* } & \text { Total lymphocyte count } \\ \text { Mid-arm muscle circumference* } & \\ \text { Urine creatinine content } / 24 \mathrm{~h} & \text { Cellular immunity* } \\ \text { Creatinine/height index } & \end{array}$


included because they are known indicators of morbidity and mortality as defined in Table 2.

\section{Prognostic indices based upon nutritional measurements}

There is little doubt that some nutritional measurements are useful in predicting adverse events in surgical patients (Buzby et al. 1980; Mullen et al. 1980; Simms et al. 1982). These authors have constructed prognostic indices based upon nutritional measurements and have been able to show that such indices can predict with considerable accuracy which patients will develop post-operative complications such as infections and wound dehiscence. All of the published indices include the biochemical measurements serum albumin and transferrin or total iron binding capacity combined with triceps skinfold thickness. The value of this method in selecting patients for nutritional therapy remains to be tested and in one study (Simms et al. I982) one index was shown to be a poor method for judging the efficacy of parenteral nutrition.

\section{The discriminatory power of biochemical measurements}

A further alternative is to identify nutritional biochemical measurements which will allow the selection of patients solely on the basis that they are malnourished. This has not been accomplished because of the difficulty of arriving at a strict definition of clinical malnutrition. However, attempts have been made to test the relative discriminatory power of nutritional measurements used either singly or in combination to allow the separation of patients into two groups, those who will need nutritional therapy and those who will not.

This work has been based on retrospective studies in which 'feed' and 'none feed' groups selected on clinical grounds have been investigated. The measurements which have the greatest discriminatory power in terms of enabling an observer to allot a patient to one or other group have been identified (Woods et al. 1981). Some of the biochemical tests are shown in Table 4 together with their discriminatory power. These results show that those measurements which are good indicators of increased morbidity and mortality are not necessarily those

\section{Table 4. The discriminatory power of single biochemical measurements}

The Table shows the percentage of patients correctly classified into 'feed' or 'none feed' groups on the basis of Fishers' discriminant function analysis applied to each measurement. A figure of $50 \%$ or less means that a toss of a coin would be more effective in classifying correctly a patient than would that measurement.

Biochemical measurement

Serum albumin concentration

Serum iron concentration

Serum sodium concentration

$24 \mathrm{~h}$ Urinary nitrogen excretion

Serum transferrin concentration

Discriminatory
power $(\%)$
$93 \cdot 4$
$70 \cdot 2$
$6 \mathrm{I} \cdot 2$
$54 \cdot 3$
$45 \cdot 9$

Discriminatory

$93 \cdot 4$

$70 \cdot 2$

$54 \cdot 3$

$45 \cdot 9$ 
Table 5. Types of chemical techniques used in nutritional assessment

I. Measurement of nutrient concentration in the blood.

2. Measurement of the urinary excretion of a nutrient.

3. Measurement of the urinary metabolites of a nutrient.

4. Detection of abnormal metabolites in urine or blood resulting from a nutrient deficiency.

5. Measurement of changes in blood constituents or enzyme activities which are dependent upon the nutrient intake.

6. Measurement of 'tissue specific' chemical markers.

7. Saturation, loading and isotope tests.

which give the clinician a reliable way of allotting a patient to a 'feed' or 'none feed' group.

\section{The interpretation of biochemical tests}

The uses of biochemical tests outlined here assume that such tests are informative in terms of an individual's nutritional state and are reliable from a technical standpoint.

Biochemical (chemical) measurements usually reflect the immediate past intake of nutrients or the changes produced by a long-standing deficient intake of a nutrient and not its current intake. They may be helpful in indicating the presence of inadequate dietary intake before the development of a biochemical lesion or a later clinical lesion which results from functional impairment of a tissue or organ. This staging of a nutrient deficiency is based on that of Pearson (1962).

The tests can be of several types (Table 5 ) but to be of clinical use a test must be widely available, simple to perform with accuracy and inexpensive. Many of the biochemical methods mentioned in the literature are clearly not applicable to clinical practice.

\section{Conclusions}

The application of nutritional assessment to hospital patients is at an early stage of development when compared to the established methods for the nutritional survey of populations. Biochemical methods are an important part of the types of assessment currently being investigated and such methods may, when they have been further developed, enable the clinician to select individual patients for nutritional therapy.

\section{REFERENCES}

Bigwood, E. J. (1939). Guideline Principles for Studies on the Nutrition of Populations. Geneva: League of Nations Health Organisation.

Bistrian, B. R., Blackburn, G. L., Hallowell, E., \& Heddle, R. (I974). F. Am. med. Ass. $230,858$.

Bistrian, B. R., Blackburn, G. L., Vitale, J., Cochran, D. \& Naylor, J. (1976). F. Am. med. Ass. 235, 1567 .

Blackburn, G. L., Bistrian, B. R., Maini, B. S., Schlamm, H. T. \& Smith, M. F. (1977). F. parent. ent. Nutr. $\mathrm{I}, \mathrm{I} \mathrm{I}$.

Bollett, A. J. \& Owens, S. O. (1973). Am. F. clin. Nutr. 26, 93 I. 
Butterworth, C. E. \& Blackburn, G. L. (1976). Nutrition Today. Teaching Aid No. I8.

Buzby, G. P., Mullen, J. L., Matthews, D. C., Hobbs, C. L. \& Rosato, E. F. (1980). Am. F. Surg. I39, 160 .

Hill, G. L., Blackett, R. L., Pickford, I., Burkinshaw, L., Young, G. A., Warren, J. W., Schorath, C. J. \& Morgan, D. B. (1977). Lancet i, 689 .

Kaminski, M. V., Fitzgerald, M. J., Murphy, R. J. (1977). F. parent. ent. Nutr. 2, 17.

Kaminski, M. V. Jr \& Winborn, A. L. (1978). Midwest Nutrition, Education and Research Foundation Inc. Chicago.

Klidjian, A. M., Foster, K. J., Kammerling, R. M., Cooper, A. \& Karran, S. J. (1980). Br. med. F. $28 \mathrm{r}, 899$.

Meakins, J. L., Pietsch, J. B., Bubenick, O., Kelly, R., Rode, H. \& Gordon, J. (1977). Ann. Surg. 186,24 I.

Mullen, J. L., Buzby, G. P., Matthews, D. C., Smale, B. F. \& Rosato, E. F. (1980). Ann. Surg. 192, 604 .

Mullen, J. L., Buzby, G. P., Waldman, T. G., Gertner, M. H., Hobbs, C. L. \& Rosato, E. F. (1979). Surg. Forum, 30, 80.

Pearson, W. N. (1962). 7. Am. med. Ass. 180, 49 .

Simms, J. M., Smith, J. A. R. \& Woods, H. F. (1982). Clin. Nutr. 1, 71.

Studley, H. O. (1936). F. Am. med. Ass. 106, $45^{8}$.

WHO ( I $\left.^{6} 6_{3}\right)$. Expert committee on medical assessment of nutritional status: Report. Technical series no. 258. Geneva: World Health Organisation.

Woods, H. F., Newton, D. J., Kay, R. \& Clark, R. G. (1980). Acta chir. scand. Supp. 507, 71.

Woods, H. F., Newton, D. J., Kay, R. \& Clark, R. G. (I981). J. Drug Res. 6, special supplement, 29. 